\title{
Clinical Management of Herpes Zoster in Patients With Rheumatoid Arthritis or Psoriatic Arthritis Receiving Tofacitinib Treatment
}

\author{
Kevin L. Winthrop · Jeffrey R. Curtis · Kunihiro Yamaoka • \\ Eun Bong Lee · Tomohiro Hirose · Jose L. Rivas · Kenneth Kwok • \\ Gerd R. Burmester
}

Received: August 18, 2021 / Accepted: October 21, 2021 / Published online: December 6, 2021

(C) The Author(s) 2021

\section{ABSTRACT}

Introduction: Risk of herpes zoster (HZ) is increased with Janus kinase inhibitor use. We evaluated clinical study data relating to $\mathrm{HZ}$ management in patients with rheumatoid arthritis (RA) or psoriatic arthritis (PsA) receiving tofacitinib.

Methods: This post hoc analysis included data from 21 RA and 3 PsA clinical studies; data were

Supplementary Information The online version contains supplementary material available at https:// doi.org/10.1007/s40744-021-00390-0.

K. L. Winthrop $(\bowtie)$

OHSU-PSU School of Public Health, Oregon Health and Science University, OHSU Mail Code

GH1043181 S.W. Sam Jackson Rd, Portland, OR 97239, USA

e-mail: winthrop@ohsu.edu

J. R. Curtis

The University of Alabama at Birmingham,

Birmingham, AL, USA

K. Yamaoka

Kitasato University School of Medicine, Sagamihara, Japan

E. B. Lee

Seoul National University College of Medicine,

Seoul, Republic of Korea

T. Hirose

Pfizer Japan Inc, Tokyo, Japan pooled for tofacitinib doses. Outcomes of $\mathrm{HZ}$ events (serious and non-serious) and tofacitinib treatment changes were evaluated in response to first and second HZ events. Median time to resolution was stratified by dermatomal involvement, history of $\mathrm{HZ}$ prior to tofacitinib, changes to tofacitinib treatment, anti-viral and corticosteroid use, and tofacitinib dose.

Results: Seven hundred eighty-three (11.1\%, $N=7061)$ patients with RA experienced $\geq 1 \mathrm{HZ}$ event, $63(8.0 \%)$ of whom had $\geq 2 \mathrm{HZ}$ events. In patients with PsA, $36(4.6 \%, N=783)$ experienced $\geq 1 \mathrm{HZ}$ event, 1 (2.8\%) of whom had $\geq 2 \mathrm{HZ}$ events. For most HZ events, tofacitinib treatment was unchanged or temporarily

J. L. Rivas

Pfizer SLU, Madrid, Spain

K. Kwok

Pfizer Inc, New York, NY, USA

G. R. Burmester

Department of Rheumatology and Clinical Immunology, Charité-Universitätsmedizin Berlin, Freie Universität Berlin and Humboldt-Universität $\mathrm{Zu}$ Berlin, Berlin, Germany 
discontinued. The majority of patients received anti-viral treatment, most within 3 days of onset. Post-herpetic neuralgia developed in $6.9 \%$ and $3.2 \%$ of patients with RA with first and second events, respectively, and in $2.8 \%$ of patients with PsA with a first event. Most first and second events resolved (RA: $97.6 \%$ and 96.8\%, respectively; PsA: $94.4 \%$ and $100 \%$, respectively). Median time to resolution was 22.0 days for first and 15.0 days for second events for RA and 20.5 days for first and 11.0 days for second events $(n=1)$ for PsA. Time to resolution of first events for RA and PsA was generally numerically shorter for patients with single dermatomal HZ, history of $\mathrm{HZ}$, or antiviral use versus those without.

Conclusion: Among patients receiving tofacitinib, recurrent events were more common in patients with RA versus PsA; HZ duration was shorter for repeat events.

Trial Registration: NCT01262118, NCT01484561, NCT00147498, NCT00413660, NCT00550446, NCT00603512, NCT00687193, NCT01164579, NCT00976599, NCT01059864, NCT01359150, NCT02147587, NCT00960440, NCT00847613, NCT00814307, NCT00856544, NCT00853385, NCT01039688, NCT02187055, NCT00413699, NCT00661661, NCT01877668, NCT01882439, NCT01976364.

\section{PLAIN LANGUAGE SUMMARY}

Patients with rheumatoid arthritis (RA) or psoriatic arthritis (PsA) have weakened immune responses and are more likely to get herpes zoster (HZ; also known as shingles) infections compared with the general population. Patients who receive treatments for RA or PsA that have an effect on their immune system are more likely to get HZ. Here, we assessed how common $\mathrm{HZ}$ was in patients with RA or PsA who were given tofacitinib during clinical trials, the management of these infections, and how this affected the course of the infection. Approximately 1 in 10 patients with RA and 1 in 20 patients with PsA had HZ. Of those patients who had HZ, 1 in 12 with RA and 1 in 36 with PsA were infected again at a later point. A small number of patients also had long-lasting pain after $\mathrm{HZ}$ infection. When patients had a $\mathrm{HZ}$ infection, most either continued treatment with tofacitinib or paused treatment for a period of time. Pausing or continuing treatment did not appear to affect how long the infection lasted or whether patients had another infection. Most patients received treatment for $\mathrm{HZ}$ infection, and patients who were treated had shorter infections. In most patients, infections cleared up and were more likely to clear up more quickly when patients had HZ previously.

Keywords: Anti-viral; Clinical management; Herpes zoster; Infections; Psoriatic arthritis; Rheumatoid arthritis; Tofacitinib

\section{Key Summary Points}

\section{Why carry out this study?}

Herpes zoster (HZ; shingles) is a common condition which can lead to debilitating complications such as post-herpetic neuralgia.

The risk of developing HZ is increased in patients with rheumatoid arthritis (RA) and psoriatic arthritis (PsA) relative to the general population, and is further increased by treatment with Janus kinase inhibitors, such as tofacitinib.

This post hoc analysis investigated $\mathrm{HZ}$ outcomes and management using data from tofacitinib RA and PsA clinical studies.

\section{What was learned from the study?}

In patients receiving tofacitinib treatment for RA or PsA, the majority of first or recurrent $\mathrm{HZ}$ events reported were nonserious, mild or moderate in severity, and were clinically manageable (e.g., with use of anti-viral therapy and/or temporary discontinuation of tofacitinib treatment), resolving in most patients. 


\section{INTRODUCTION}

Herpes zoster (HZ), also known as shingles, is a common condition with an incidence rate (IR) of 3-5 cases per 1000 person-years among the general population in Asia-Pacific, Europe, and North America [1]. The condition is typically characterized by a painful rash that can lead to debilitating complications, such as post-herpetic neuralgia (PHN) [1, 2], and occurs when latent varicella zoster virus (VZV), the causative agent of varicella (chickenpox), is re-activated in neurons when the immune response is diminished [2]. Compared with the general population, HZ risk is greater in older [1] and immunocompromised people [2], and in particular those with autoimmune conditions such as rheumatoid arthritis (RA) or psoriatic arthritis (PsA), where the risk is approximately twothreefold higher than for age-matched healthy individuals [3]. This risk can be further increased with the use of immunosuppressants, such as corticosteroids, biologic disease-modifying antirheumatic drugs (bDMARDs) [4], and Janus kinase (JAK) inhibitors [5].

Tofacitinib is an oral JAK inhibitor for the treatment of RA and PsA. In prior analyses of infection risk within the tofacitinib clinical development program for RA, HZ risk was higher for tofacitinib- versus placebo-treated patients, with IRs (patients with events per 100 patient-years [PY] of exposure) (95\% confidence interval $[\mathrm{CI}])$ of $4.4(3.8,4.9)$ and $1.5(0.5,4.6)$, respectively [6]. Similar findings were observed in the tofacitinib clinical development programs for PsA and psoriasis, but the rates of $\mathrm{HZ}$ with tofacitinib were lower versus patients with RA [7-10]. Interestingly, no cases of visceral HZ were reported in the RA clinical development program [6], and most cases (90.2\%) of HZ reportedly involved a single dermatome, with multidermatomal or disseminated cases less common [11]. In patients with RA, the risk of developing $\mathrm{HZ}$ while receiving tofacitinib has been reported to increase further with increasing age, corticosteroid and conventional synthetic (cs) DMARD use, increasing tofacitinib dose, and enrollment within Asia (patients from Japan and Korea had approximately two-threefold higher rates of $\mathrm{HZ}$ versus those from the Americas or Europe in clinical studies) [12]. Similarly, in the RA clinical development programs for baricitinib [13] and upadacitinib [14], elevated HZ rates were observed versus placebo, with the highest rates reported in Asia. Longer term studies are required to establish whether differences in JAK selectivity will have any impact on risk between individual JAK inhibitors [15].

The mechanism for increased $\mathrm{HZ}$ risk with tofacitinib is considered to be multifactorial and is not well understood $[6,16]$. Tofacitinibmediated suppression of interferon (IFN) $\gamma$ signaling [17] may play a role, as IFN $\gamma$ is involved in the inhibition of VZV replication [18]. A recent genetic analysis also identified multiple loci that were associated with increased risk of $\mathrm{HZ}$ in patients with RA or psoriasis receiving tofacitinib [19].

While prior studies have characterized the increased HZ risk with JAK inhibitors [20], the clinical management of these events has not been previously detailed. It is also unclear how factors such as anti-viral use or continued/discontinued use of JAK inhibitors affect clinical outcomes. Accordingly, we sought to retrospectively evaluate how HZ events, and their sequelae, were clinically managed during the RA and PsA tofacitinib clinical development programs.

\section{METHODS}

\section{Patients and Study Design}

This was a post hoc analysis of data from patients enrolled in clinical studies of tofacitinib for the treatment of RA or PsA.

For RA, data up to March 2017 were pooled from two phase 1 , ten phase 2 , six phase 3 , one phase $3 \mathrm{~b} / 4$, and two long-term extension (LTE) studies (Table $\mathrm{S} 1$ ). Patients were aged $\geq 18$ years and received tofacitinib (most commonly 5 or $10 \mathrm{mg}$ twice daily [BID]) as monotherapy or in combination with csDMARDs.

For PsA, data up to July 2019 were pooled from two phase 3 studies and one LTE study (Table S2). Patients were aged $\geq 18$ years and 
received tofacitinib 5 or $10 \mathrm{mg}$ BID in combination with csDMARDs.

Full details of study designs and inclusion/ exclusion criteria have previously been published (see Tables S1 and S2). The studies were conducted in accordance with the Declaration of Helsinki, the International Council for Harmonisation Guidelines for Good Clinical Practice, and local regulations. All patients provided informed consent, and Institutional Review Board approval was provided by all participating institutions.

\section{Outcomes}

Outcomes were evaluated in tofacitinib-treated patients who were clinically determined to have HZ (serious and non-serious) during these studies. The number of $\mathrm{HZ}$ events, including recurrence of $\mathrm{HZ}$ ( $\geq 2$ events), and for first and second HZ events, seriousness and severity of events, as well as occurrence of subsequent PHN events, were reported. The number of subsequent $\mathrm{HZ}$ events following second $\mathrm{HZ}$ events was also reported, but was not evaluated in detail. HZ events were defined as serious if they were life-threatening or resulted in any of the following: inpatient hospitalization or prolongation of existing hospitalization; persistent or significant disability/incapacity; congenital anomaly/birth defect; or death. Patients who experienced serious events were discontinued from the study. For the severity assessment, the adjectives mild, moderate, or severe were used to describe the maximum intensity of the $\mathrm{HZ}$ event. HZ events were resolved if they had both onset and resolution dates.

Changes to tofacitinib treatment in response to the first and second (recurrent) HZ events were evaluated and included permanent discontinuation, temporary discontinuation, dose reduction, no action taken, and unknown action (included post-treatment HZ events). Disease activity in patients with RA within 90 days after the first $\mathrm{HZ}$ event was assessed using the Disease Activity Score in 28 joints, erythrocyte sedimentation rate (DAS28-4[ESR]), stratified by changes to tofacitinib treatment.
Use of anti-viral therapy for systemic use was evaluated for all $\mathrm{HZ}$ events.

Median (with interquartile range [IQR]) and mean time to resolution of first and second HZ events (calculated for patients with resolved HZ, i.e., $\mathrm{HZ}$ events for which there was both date of onset and resolution) were evaluated and stratified by: dermatome involvement (single dermatomal; multidermatomal [occurring in nonadjacent or $>2$ adjacent dermatomes, or disseminated]); history of $\mathrm{HZ}$ prior to tofacitinib treatment, changes to tofacitinib treatment (permanent discontinuation; temporary discontinuation; dose reduction; no action taken; unknown action); anti-viral use; prior corticosteroid use; and average tofacitinib dose (5 or $10 \mathrm{mg}$ BID; defined as the average daily dose at the end of enrollment up to the cut-off date of $<15$ or $\geq 15 \mathrm{mg}$, respectively).

\section{Statistical Analyses}

Data were evaluated separately for RA and PsA clinical studies, with data pooled for all tofacitinib doses.

Descriptive statistical analyses included all reported events. The IR and 95\% CI (calculated via the Exact Poisson method, adjusted for exposure time) for $\mathrm{HZ}$ was based on the number of unique patients (per $100 \mathrm{PY}$ of exposure) with a HZ event, with follow-up time calculated to the date of the first event, subject to a risk period of 28 days beyond the last tofacitinib dose, or to the data cut-off date. The IR and 95\% CI for recurrence were based on the number of unique patients (per $100 \mathrm{PY}$ of exposure) with second HZ events, with follow-up time calculated from 30 days after the resolution of the first $\mathrm{HZ}$ event through to the last tofacitinib dose plus 28 days, or censored at the date of occurrence of the second event, whichever occurred earlier. Kaplan-Meier estimates of the second $\mathrm{HZ}$ event, presented through the time after the first HZ event to second HZ event onset, were calculated and plotted.

Categorical variables were summarized with frequency counts and percentages, and continuous variables were summarized descriptively with mean and standard deviation or median 
and IQR. Demographic and baseline characteristics were summarized for patients reporting one, multiple ( $\geq 2)$, or no HZ events (RA), or for patients reporting $\geq 1$ and no HZ events (PsA). The time to HZ resolution for first and second $\mathrm{HZ}$ events was calculated based on the onset date and end date in the Adverse Event (AE) Report form. Missing end dates for resolved $\mathrm{HZ}$ events were imputed using the latest available date of onset or AE collection. The following variables were used in stratified analyses of time to resolution for first and second $\mathrm{HZ}$ events: number of involved dermatomes (single or multiple) during $\mathrm{HZ}$ event (for time to resolution only); history of HZ (yes/no), where history of $\mathrm{HZ}$ was defined as medical history of $\mathrm{HZ}$ prior to the first tofacitinib dose; changes to tofacitinib treatment following $\mathrm{HZ}$ event; antiviral use during $\mathrm{HZ}$ event (yes/no); corticosteroid use within 14 days prior to the $\mathrm{HZ}$ event (yes/no); and average tofacitinib dose (5 or $10 \mathrm{mg}$ BID).

\section{RESULTS}

\section{Patients with RA}

\section{Patient Demographics and Baseline Disease Characteristics}

This post hoc analysis included data from 7061 patients with RA who received tofacitinib $(22,875$ PY of exposure overall), of whom 783 (11.1\%) experienced $\geq 1 \mathrm{HZ}$ event, with an IR $(95 \% \mathrm{CI})$ of $3.6(3.4,3.9)$ per $100 \mathrm{PY}$. None of the patients had been vaccinated against HZ, and $2.3 \%$ of patients who went on to experience $\geq 1 \mathrm{HZ}$ event had a history of HZ before tofacitinib treatment. Patients of Asian ethnicity, or those who enrolled at sites in Asia, accounted for a numerically higher proportion of those who experienced HZ events, compared with those who did not (Table 1). A numerically higher proportion of patients who experienced $\mathrm{HZ}$ events were aged $>45-<65$ years versus those without HZ events (Table 1). Baseline demographics and clinical characteristics were generally similar between patients who experienced single $(n=720)$ or multiple $(\geq 2$; $n=63) \mathrm{HZ}$ events (Table 1 ).

\section{HZ Events and PHN}

Of the 783 first HZ events, most (95.5\%) were mild or moderate in severity (Table 2). Serious first $\mathrm{HZ}$ events occurred in $7.0 \%$ of patients (Table 2 ) and were mostly moderate $(58.2 \%)$ or severe $(32.7 \%)$. Overall, $6.9 \%$ of first $\mathrm{HZ}$ events were followed by PHN (Table 2). Recurrence of $\mathrm{HZ}$ ( $\geq 2$ events) was reported in $8.0 \%(n=63 /$ 783) of patients: 50 patients had two events, 10 patients had three events, 2 patients had four events, and 1 patient had five events. The IR (95\% CI) of second HZ events was $3.7(2.8,4.7)$, based on events that occurred within 28 days of the last tofacitinib dose, with a median (IQR) follow-up period of $3.2(2.1,4.5)$ years following the first non-serious HZ event. Most second HZ events occurred within 3 years of the first event, with survival rates of approximately $88 \%$ and $86 \%$ at month 36 and month 72 , respectively (Fig. 1). Of the $63 \mathrm{HZ}$ events, $4.8 \%$ were serious, $98.4 \%$ were mild or moderate in severity, and $3.2 \%$ were followed by PHN (Table 2). Overall, $117 \mathrm{HZ}$ events were reported within 90 days of the patients' last study visit, 13 of which were ongoing at the patients' last visit.

\section{HZ Management and Outcomes}

After the first HZ event, tofacitinib was temporarily discontinued in $42.8 \%$ of patients, with a mean (range) length of temporary discontinuation of 16.3 (1-98) days, and permanently discontinued in $9.1 \%$ of patients; no changes were made to treatment in $47.3 \%$ of patients (Fig. 2a). Similar trends were observed in those experiencing a second HZ event (Figure S1). For most patients with mild first HZ events no changes were made to tofacitinib treatment; a similar proportion of those with moderate first $\mathrm{HZ}$ events had no change or temporarily discontinued tofacitinib (Fig. 2a), while permanent discontinuation was the most common action taken by patients who had a severe first HZ event (Fig. 2a). The mean of the first DAS284(ESR) score measured within 90 days of the first $\mathrm{HZ}$ event was similar, regardless of changes to tofacitinib treatment (permanent discontinuation $=3.9$; temporary discontinuation $=3.7$; dose reduction $=3.9$; no action taken $=3.5$; unknown action $=4.5$ ). 
Table 1 Baseline demographic and clinical characteristics of patients with RA receiving tofacitinib, stratified by number of $\mathrm{HZ}$ events

\begin{tabular}{|c|c|c|c|}
\hline & $\begin{array}{l}1 \mathrm{HZ} \text { event } \\
(N=720)\end{array}$ & $\begin{array}{l}\geq 2 \mathrm{HZ} \text { events } \\
(N=63)\end{array}$ & $\begin{array}{l}\text { No } \mathrm{HZ} \text { events } \\
(N=6278)\end{array}$ \\
\hline Age, mean (SD), years & $55.4(10.1)$ & $56.0(9.3)$ & $51.6(12.1)$ \\
\hline \multicolumn{4}{|l|}{ Age, $n(\%)$, years } \\
\hline $18-45$ & $118(16.4)$ & $8(12.7)$ & $1791(28.5)$ \\
\hline$>45-<65$ & $470(65.3)$ & $44(69.8)$ & $3611(57.5)$ \\
\hline$\geq 65$ & $132(18.3)$ & $11(17.5)$ & $876(14.0)$ \\
\hline Female, $n(\%)$ & $600(83.3)$ & $57(90.5)$ & $5172(82.4)$ \\
\hline \multicolumn{4}{|l|}{ Race, $n(\%)$} \\
\hline White & $409(56.8)$ & $35(55.6)$ & $4132(65.8)$ \\
\hline Black & $17(2.4)$ & 0 & $202(3.2)$ \\
\hline Asian & $234(32.5)$ & $23(36.5)$ & $1309(20.9)$ \\
\hline Other & $60(8.3)$ & $5(7.9)$ & $635(10.1)$ \\
\hline \multicolumn{4}{|l|}{ Geographic region, $n(\%)$} \\
\hline US/Canada & $168(23.3)$ & $22(34.9)$ & $1555(24.8)$ \\
\hline Europe & $179(24.9)$ & $13(20.6)$ & $2190(34.9)$ \\
\hline Latin America & $118(16.4)$ & $5(7.9)$ & $1098(17.5)$ \\
\hline Asia & $255(35.4)$ & $23(36.5)$ & $1395(22.2)$ \\
\hline Rest of world & 0 & 0 & $40(<1.0)$ \\
\hline BMI, $n(\%), \mathrm{kg} / \mathrm{m}^{2}$ & $26.7(6.4)$ & $27.8(7.7)$ & $27.2(6.4)^{\mathrm{a}}$ \\
\hline \multicolumn{4}{|l|}{ Smoking status, $n$ (\%) } \\
\hline Current & $87(12.1)$ & $6(9.5)$ & $1105(17.6)$ \\
\hline Former & $154(21.4)$ & $15(23.8)$ & $1010(16.1)$ \\
\hline Never & $467(64.9)$ & $42(66.7)$ & $3961(63.1)$ \\
\hline Unknown & $12(1.7)$ & 0 & $202(3.2)$ \\
\hline \multicolumn{4}{|l|}{ Prior therapy, $n(\%)$} \\
\hline MTX & $606(84.2)$ & $51(81.0)$ & $5101(81.3)$ \\
\hline Non-bDMARD ${ }^{b}$ & $421(58.5)$ & $34(54.0)$ & $3181(50.7)$ \\
\hline TNFi & $124(17.2)$ & $16(25.4)$ & $998(15.9)$ \\
\hline Non-TNFi bDMARD & $40(5.6)$ & $5(7.9)$ & $310(4.9)$ \\
\hline Concomitant corticosteroids, $n$ (\%) & $439(61.0)$ & $41(65.1)$ & $3492(55.6)$ \\
\hline Diabetes, $n(\%)$ & $58(8.1)$ & $3(4.8)$ & $501(8.0)$ \\
\hline History of $\mathrm{HZ}$ prior to receiving tofacitinib, $n$ (\%) & $16(2.2)$ & $2(3.2)$ & $96(1.5)$ \\
\hline
\end{tabular}


Table 1 continued

\begin{tabular}{llll}
\hline & $\begin{array}{l}\text { 1 HZ event } \\
(N=720)\end{array}$ & $\begin{array}{c}\geq 2 \mathrm{HZ} \text { events } \\
(N=63)\end{array}$ & $\begin{array}{l}\text { No HZ events } \\
(N=6278)\end{array}$ \\
\hline HZ vaccination, $n(\%)$ & 0 & 0 & 0 \\
\hline
\end{tabular}

Patients received mainly tofacitinib 5 or $10 \mathrm{mg}$ BID as monotherapy or in combination with csDMARDs in phase 1 , phase 2, phase 3, phase $3 \mathrm{~b} / 4$, and LTE studies

bDMARD biologic disease-modifying antirheumatic drug, BID twice daily, BMI body mass index, csDMARD conventional synthetic disease-modifying antirheumatic drug, $H Z$ herpes zoster, LTE long-term extension, MTX methotrexate, $N$ number of patients with non-missing data, $n$ number of patients with characteristic, $R A$ rheumatoid arthritis, $S D$ standard deviation, $T N F i$ tumor necrosis factor inhibitor

${ }^{\mathrm{a}} N=6273$

bother than MTX

Table 2 Seriousness and severity of first and second $\mathrm{HZ}$ events, and subsequent PHN, in patients with RA receiving tofacitinib

\begin{tabular}{lll}
\hline & $\begin{array}{l}\text { First HZ } \\
\text { event } \\
(\boldsymbol{N}=783)\end{array}$ & $\begin{array}{l}\text { Second HZ } \\
\text { event }^{\mathbf{a}} \\
(\boldsymbol{N}=\mathbf{6 3})\end{array}$ \\
\hline $\begin{array}{l}\text { Seriousness, } n(\%) \\
\text { Serious }\end{array}$ & $55(7.0)$ & $3(4.8)$ \\
Non-serious & $728(93.0)$ & $60(95.2)$ \\
Severity, $n(\%)$ & $336(42.9)$ & $36(57.1)$ \\
Mild & $412(52.6)$ & $26(41.3)$ \\
Moderate & $34(4.3)$ & $1(1.6)$ \\
Severe & $1(0.1)$ & 0 \\
Unknown & $54(6.9)$ & $2(3.2)$ \\
\hline Subsequent PHN, $n(\%)$ & & \\
\hline
\end{tabular}

$H Z$ herpes zoster, $N$ number of patients with non-missing data, $n$ unique number of patients with event, $P H N$ postherpetic neuralgia, $R A$ rheumatoid arthritis

${ }^{a}$ Data are presented for the second event that occurred in patients who experienced multiple $\mathrm{HZ}$ events. Some patients experienced $3(n=10), 4(n=2)$, or $5(n=1)$ HZ events; however, data for third or subsequent events are not included here
All three patients with serious second HZ events temporarily discontinued tofacitinib treatment following their first event (Table 3). The proportion of patients with non-serious second $\mathrm{HZ}$ events was similar in those who temporarily discontinued tofacitinib versus those who continued treatment with no change following their first $\mathrm{HZ}$ event, while fewer patients who permanently discontinued tofacitinib experienced non-serious second $\mathrm{HZ}$ events versus those who temporarily discontinued or continued tofacitinib; however, sample numbers were lower in this group (Table 3 ).

Of all 783 patients experiencing HZ, 87.5\% received anti-viral treatment following their first HZ event (Fig. 2b) and a similar proportion $(90.5 \%)$ received anti-viral treatment following their second HZ event. The most commonly used anti-viral treatment was aciclovir, which nearly half of all patients received (Figure S2). Most patients who did not receive anti-viral treatment following their first HZ event experienced events that were reported as mild (Fig. 2b). Most patients (69.5\%) received antiviral treatment within 3 days of first $\mathrm{HZ}$ onset. In patients who received anti-viral treatment for their first $\mathrm{HZ}$ event, $8.0 \%$ and $0.3 \%$, respectively, had non-serious and serious second HZ events, with similar results in those who received treatment within 3 days (Table 3 ). In patients who did not receive anti-viral 


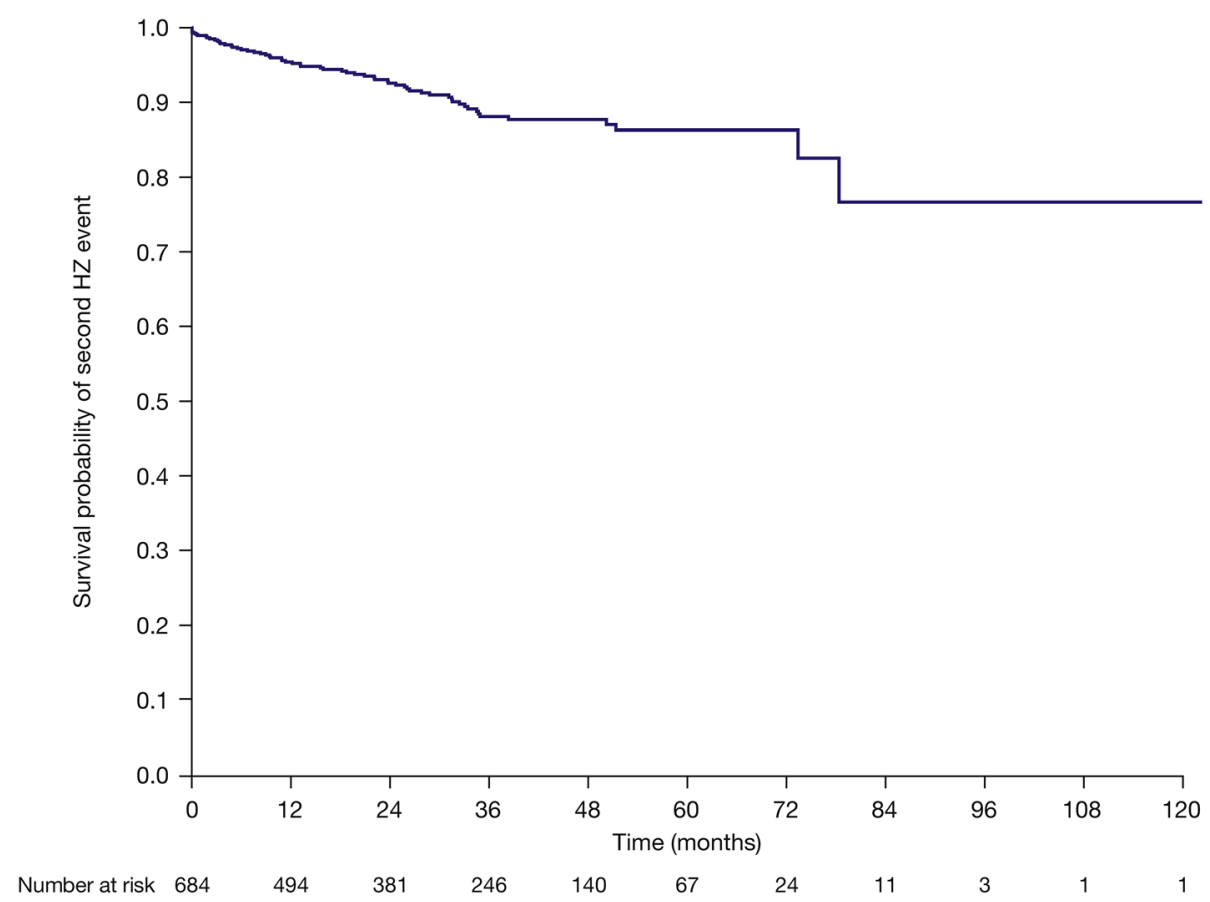

Fig. 1 Kaplan-Meier plot of time to second $\mathrm{HZ}$ event following the first $\mathrm{HZ}$ event in patients with $\mathrm{RA}$ receiving tofacitinib. Kaplan-Meier estimates of the second $\mathrm{HZ}$ event are presented from the end of the first $\mathrm{HZ}$ event to the occurrence of the second $\mathrm{HZ}$ event. Patients whose first $\mathrm{HZ}$ end date occurred either after the date of onset of

treatment for their first $\mathrm{HZ}$ event, 5.1\% and $1.0 \%$ had non-serious and serious second $\mathrm{HZ}$ events, respectively (Table 3 ).

The proportion of patients who experienced PHN following their first HZ event was numerically higher in those who temporarily discontinued tofacitinib, versus all other changes to tofacitinib treatment and in patients who received anti-viral treatment for the $\mathrm{HZ}$ event versus those who did not (Table 4). PHN following the first $\mathrm{HZ}$ event was more common in patients who received anti-viral treatment for the $\mathrm{HZ}$ event compared with those who received no anti-viral treatment (Table 4); however, comparatively fewer patients did not receive anti-viral treatment. A similar result was observed in patients who received anti-viral treatment specifically within 3 days of $\mathrm{HZ}$ onset versus those who did not receive anti-viral treatment (Table 4). the second $\mathrm{HZ}$ event, or after the last dose of tofacitinib with no second $\mathrm{HZ}$ event, were excluded from this analysis. The last second HZ event occurred at $\sim$ month 78 , with 13 patients remaining at risk beyond this point. The final month of observation was month 122. $H Z$ herpes zoster, $R A$ rheumatoid arthritis

$\mathrm{HZ}$ events were resolved in most patients (97.6\% for first events and $96.8 \%$ for second events), and for the remaining patients, the event was ongoing at data cut-off or the outcome was unknown. Time to resolution was numerically shorter for second $\mathrm{HZ}$ events (median, 15.0 days; mean, 24.1 days) versus first events (median, 22.0 days; mean, 37.6 days) (Fig. 3) and a small proportion $(7.1 \%, n=54)$ of first $\mathrm{HZ}$ events resolved after $>90$ days. For the 764 first HZ events with onset and resolution dates, median time to resolution was numerically shorter for patients with a history of $\mathrm{HZ}$ prior to tofacitinib versus no history (16.5 vs. 22 days) and somewhat shorter for single dermatomal versus multidermatomal cases ( 21.0 vs. 25 days), anti-viral use within 3 days versus no use (18.0 vs. 24.0 days), and corticosteroid use versus no use (21.0 vs. 23.0 days) (Fig. 3a). For second HZ events, median time to resolution was numerically shorter for patients 

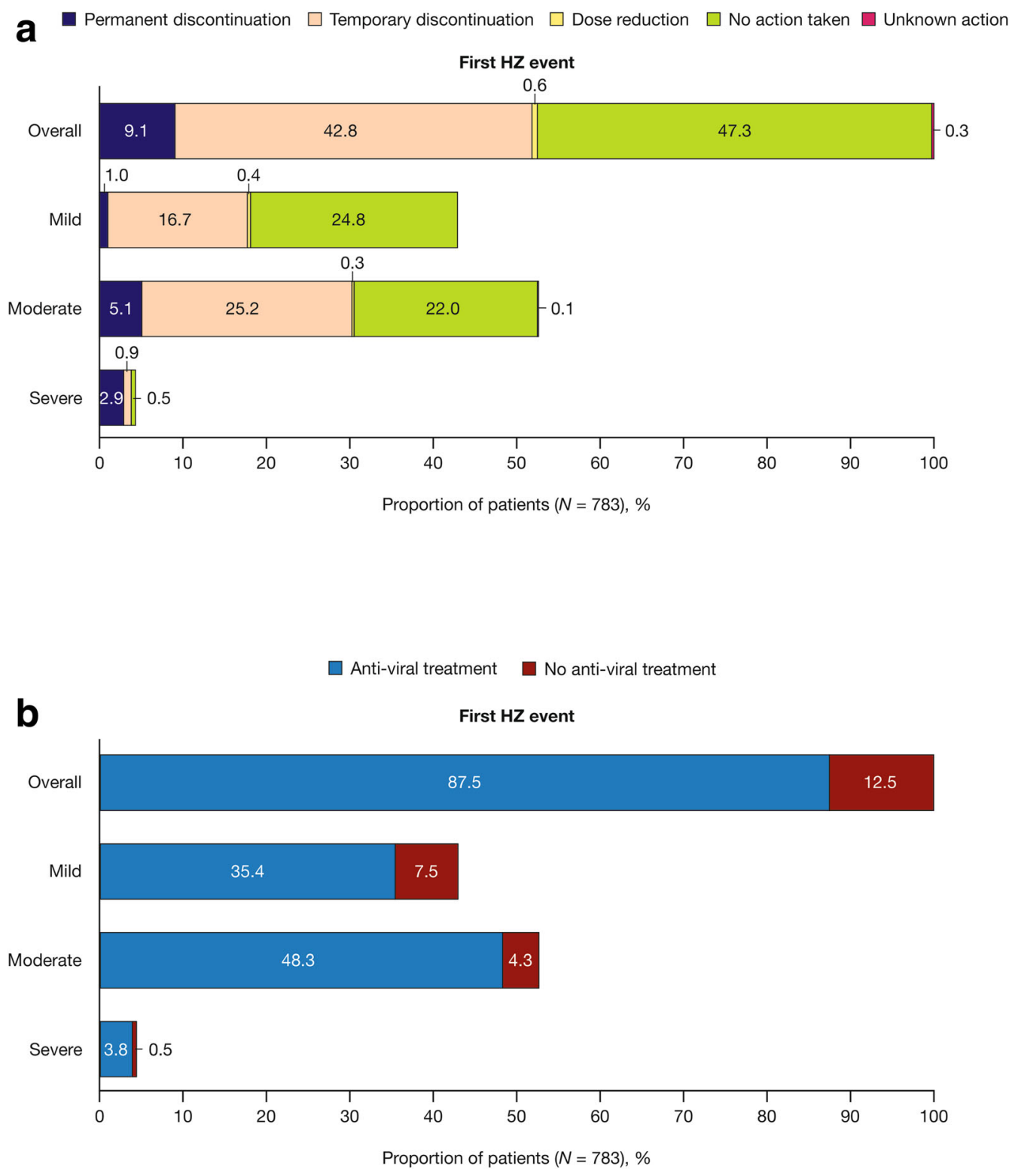

Fig. 2 Responses to $\mathrm{HZ}$ in patients with $\mathrm{RA}$ receiving tofacitinib: a changes to tofacitinib treatment due to first $\mathrm{HZ}$ event, stratified by event severity, and $\mathbf{b}$ anti-viral use due to first $\mathrm{HZ}$ event, stratified by event severity. One patient with unknown $\mathrm{HZ}$ severity had unknown action

with temporary discontinuation of tofacitinib versus those for whom no action was taken (median 12.5 vs. 21.0 days) and longer for those with a history of $\mathrm{HZ}$ prior to tofacitinib versus no history (39.0 vs. 14.0 days) (Fig. 3b). Time to resolution of second $\mathrm{HZ}$ events was shorter for patients with anti-viral use within 3 days of the and received no anti-viral therapy; this patient is included in the overall values presented. $H Z$ herpes zoster, $N$ number of patients with first $\mathrm{HZ}$ event, $R A$ rheumatoid arthritis

second $\mathrm{HZ}$ event versus no anti-viral use (median 13.0 vs. 18.0 days) and for patients receiving an average tofacitinib dose of $10 \mathrm{mg}$ BID versus $5 \mathrm{mg}$ BID (median 13.0 vs. 26.5 days) (Fig. 3b).

In patients with RA receiving tofacitinib, there were no deaths due to $\mathrm{HZ}$, while 118 
Table 3 The effect of management of the first $\mathrm{HZ}$ event on the occurrence of second $\mathrm{HZ}$ events (serious and non-serious) in patients with RA who had $\geq 2 \mathrm{HZ}$ events

\begin{tabular}{lll}
\hline & $\begin{array}{l}\text { Non-serious second HZ event } \\
(\boldsymbol{N}=\mathbf{6 0})\end{array}$ & $\begin{array}{l}\text { Serious second HZ event } \\
(\boldsymbol{N}=\mathbf{3})\end{array}$ \\
\hline $\begin{array}{l}\text { Change to tofacitinib treatment due to first HZ } \\
\text { event, } n(\%)^{\mathrm{a}}\end{array}$ & $1(50.0)$ & 0 \\
Unknown action $(N=2)$ & $1(1.4)$ & 0 \\
Permanent discontinuation $(N=71)$ & $27(8.1)$ & $3(0.9)$ \\
Temporary discontinuation $(N=335)$ & 0 & 0 \\
Dose reduction $(N=5)$ & $31(8.4)$ & 0 \\
No action taken $(N=370)$ & & $2(0.3)$ \\
Anti-viral treatment due to first $\mathrm{HZ}$ event, $n(\%)^{\mathrm{a}}$ & $25(8.0)$ & $2(0.4)$ \\
Anti-viral use $(N=685)$ & $40(8.4)$ & $1(1.0)$ \\
Anti-viral use within 3 days $(N=476)$ & $5(5.1)$ & \\
No anti-viral use $(N=98)$ &
\end{tabular}

$H Z$ herpes zoster, $N$ number of patients in each category, $n$ number of patients in each category with second HZ event, $R A$ rheumatoid arthritis

${ }^{a}$ Proportion calculated based on the number of patients with first $\mathrm{HZ}$ events who had corresponding changes to tofacitinib treatment or anti-viral use

Table 4 Patients with RA who experienced PHN following the first $\mathrm{HZ}$ event, stratified by changes to tofacitinib treatment and anti-viral use due to first $\mathrm{HZ}$ event

PHN following first $\mathrm{HZ}$ event $(N=54)$

Change to tofacitinib treatment due to first $\mathrm{HZ}$ event, $n(\%)^{\mathrm{a}}$

Unknown action $(N=2)$

Permanent discontinuation $(N=71)$

Temporary discontinuation $(N=335)$

Dose reduction $(N=5)$

No action taken $(N=370)$

Anti-viral treatment due to first $\mathrm{HZ}$ event, $n(\%)^{\mathrm{a}}$

Anti-viral use $(N=685)$

Anti-viral use within 3 days $(N=476)$

No anti-viral use $(N=98)$
0

$35(10.4)$

0

$15(4.1)$

$53(7.7)$

$38(8.0)$

$1(1.0)$

$H Z$ herpes zoster, $N$ number of patients in each category, $n$ number of patients in each category with subsequent PHN, $P H N$ post-herpetic neuralgia, $R A$ rheumatoid arthritis

${ }^{a}$ Proportion calculated based on the number of patients with first $\mathrm{HZ}$ events who had corresponding changes to tofacitinib treatment or anti-viral use 

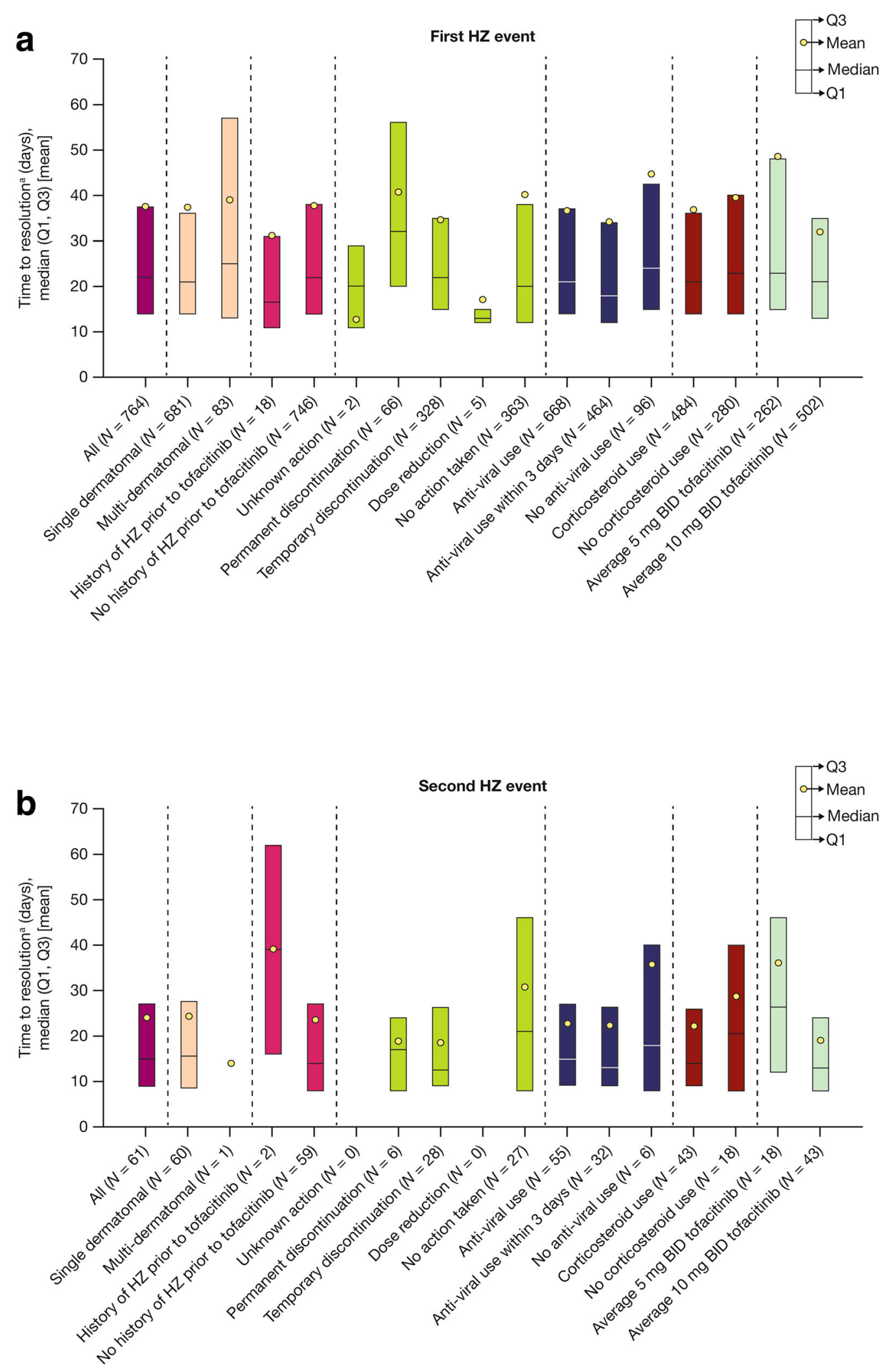
4 Fig. 3 Time to resolution ${ }^{\mathrm{a}}$ of a first $\mathrm{HZ}$ event and b second $\mathrm{HZ}$ event in patients with RA, stratified by dermatome involvement, history of $\mathrm{HZ}^{\mathrm{b}}$, changes to tofacitinib treatment, anti-viral use, corticosteroid use ${ }^{c}$, and average tofacitinib dose. ${ }^{a}$ Time to resolution in patients with both a date of onset and date of resolution for the $\mathrm{HZ}$ event. ${ }^{\mathrm{b}}$ Medical history of $\mathrm{HZ}$ prior to the first dose of tofacitinib. ${ }^{\mathrm{c}}$ Corticosteroid use within 14 days prior to the $\mathrm{HZ}$ event. BID twice daily, $H Z$ herpes zoster, $N$ number of patients with non-missing data, $Q 1$ first quartile (25th percentile), Q3 third quartile (75th percentile), $R A$ rheumatoid arthritis

deaths $(1.7 \%$ of $N=7061)$ were reported due to other events, 59 of which occurred within 28 days of the last tofacitinib dose. Deaths due to events other than HZ occurred in 12 (1.5\%) patients with $\mathrm{HZ}$ and $106(1.7 \%)$ patients without HZ. Overall, 276 (35.2\%) patients with HZ were hospitalized compared with 1425 $(22.7 \%)$ patients without HZ. Of the 276 patients with $\mathrm{HZ}$ who were hospitalized, 52 (6.6\% of patients with $\mathrm{HZ}$ ) were hospitalized specifically because of their $\mathrm{HZ}$ event while the remainder $(N=224 ; 28.6 \%$ of patients with $\mathrm{HZ})$ were hospitalized because of other events.

\section{Patients with PsA}

\section{Patient Demographics and Baseline Disease Characteristics}

This post hoc analysis included 783 patients with PsA who received tofacitinib (2046 of PY exposure) of whom $36 \quad(4.6 \%)$ experienced $\geq 1 \mathrm{HZ}$ event, with an IR $(95 \% \mathrm{CI})$ of $1.8(1.2,2.4)$ per $100 \mathrm{PY}$. None of the patients had been vaccinated against $\mathrm{HZ}$, and $5.0 \%$ of patients who went on to experience $\geq 1 \mathrm{HZ}$ event had a history of HZ before tofacitinib treatment (Table 5). A numerically higher proportion of patients with $\geq 1 \mathrm{HZ}$ event were aged 45-64 years versus those without an event (Table 5). There was a numerically higher proportion of patients with a history of $\mathrm{HZ}$ prior to tofacitinib among those reporting $\geq 1 \mathrm{HZ}$ event versus those with no $\mathrm{HZ}$ events $(13.9 \%$ and $4.6 \%$, respectively) (Table 5). The number of patients with HZ events was small, however, and the results should be interpreted with caution.
Table 5 Baseline demographic and clinical characteristics of patients with PsA receiving tofacitinib, stratified by number of $\mathrm{HZ}$ events

\begin{tabular}{|c|c|c|}
\hline & $\begin{array}{l}\geq 1 \mathrm{HZ} \\
\text { event } \\
(N=36)\end{array}$ & $\begin{array}{l}\text { No } \mathrm{HZ} \text { event } \\
(N=747)\end{array}$ \\
\hline Age, mean (SD), years & $49.0(11.3)$ & $48.7(12.0)$ \\
\hline \multicolumn{3}{|l|}{ Age, $n(\%)$, years } \\
\hline $18-44$ & $10(27.8)$ & $277(37.1)$ \\
\hline $45-64$ & $23(63.9)$ & $401(53.7)$ \\
\hline$\geq 65$ & $3(8.3)$ & $69(9.2)$ \\
\hline Female, $n(\%)$ & $22(61.1)$ & $406(54.4)$ \\
\hline \multicolumn{3}{|l|}{ Race, $n(\%)$} \\
\hline White & $34(94.4)$ & $705(94.4)$ \\
\hline Black & 0 & $3(0.4)$ \\
\hline Asian & $1(2.8)$ & $22(2.9)$ \\
\hline Other & $1(2.8)$ & $17(2.3)$ \\
\hline \multicolumn{3}{|l|}{ Geographic region, $n(\%)$} \\
\hline US/Canada & $10(27.8)$ & $148(19.8)$ \\
\hline $\begin{array}{l}\text { Australasia/ } \\
\text { Western Europe }\end{array}$ & $12(33.3)$ & $161(21.6)$ \\
\hline Russia/Eastern Europe & $12(33.3)$ & $357(47.8)$ \\
\hline Latin America & $1(2.8)$ & $67(9.0)$ \\
\hline Asia & $1(2.8)$ & $14(1.9)$ \\
\hline BMI, $n(\%), \mathrm{kg} / \mathrm{m}^{2}$ & $29.4(6.1)$ & $29.6(6.0)$ \\
\hline \multicolumn{3}{|l|}{ Smoking status, $n$ (\%) } \\
\hline Current & $5(13.9)$ & $135(18.1)$ \\
\hline Former & $8(22.2)$ & $150(20.1)$ \\
\hline Never & $23(63.9)$ & $462(61.8)$ \\
\hline \multicolumn{3}{|l|}{ Prior therapy, $n(\%)$} \\
\hline MTX & $31(86.1)$ & $694(92.9)$ \\
\hline Non-bDMARD ${ }^{a}$ & $17(47.2)$ & $353(47.3)$ \\
\hline TNFi & $19(52.8)$ & $358(47.9)$ \\
\hline Non-TNFi bDMARD & $2(5.6)$ & $44(5.9)$ \\
\hline $\begin{array}{l}\text { Concomitant } \\
\text { corticosteroids, } n(\%)\end{array}$ & $7(19.4)$ & $164(22.0)$ \\
\hline
\end{tabular}


Table 5 continued

\begin{tabular}{lll}
\hline & $\begin{array}{l}\geq \mathbf{1 ~ H Z} \\
\text { event } \\
(\boldsymbol{N}=\mathbf{3 6})\end{array}$ & $\begin{array}{l}\text { No } \mathbf{H Z} \text { event } \\
(\boldsymbol{N}=\mathbf{7 4 7})\end{array}$ \\
\hline Diabetes, $n(\%)$ & $5(13.9)$ & $102(13.7)$ \\
$\begin{array}{l}\text { History of HZ prior to } \\
\text { tofacitinib, } n \text { (\%) }\end{array}$ & $5(13.9)$ & $34(4.6)$ \\
HZ vaccination, $n(\%)$ & 0 & 0 \\
\hline
\end{tabular}

Patients received tofacitinib 5 or $10 \mathrm{mg}$ BID in combination with a single csDMARD in phase 3 and LTE studies

LDMARD biologic disease-modifying antirheumatic drug, $B I D$ twice daily, $B M I$ body mass index, csDMARD conventional synthetic disease-modifying antirheumatic drug, $H Z$ herpes zoster, LTE long-term extension, $M T X$ methotrexate, $N$ number of patients with nonmissing data; $n$ number of patients with characteristic, $P_{S} A$ psoriatic arthritis, $S D$ standard deviation, TNFi tumor necrosis factor inhibitor

${ }^{a}$ Other than MTX

Table 6 Seriousness and severity of first $\mathrm{HZ}$ events, and subsequent PHN, in patients with PsA receiving tofacitinib

First $\mathrm{HZ}$ events $(N=36)$

\begin{tabular}{ll}
\hline $\begin{array}{l}\text { Seriousness, } n \text { (\%) } \\
\text { Serious }\end{array}$ & $1(2.8)$ \\
Non-serious & $35(97.2)$ \\
Severity, $n$ (\%) & \\
Mild & $15(41.7)$ \\
Moderate & $20(55.6)$ \\
Severe & $1(2.8)$ \\
Subsequent PHN, $n(\%)$ & $1(2.8)$
\end{tabular}

$H Z$ herpes zoster, $N$ number of patients with non-missing data, $n$ unique number of patients with event, $P H N$ postherpetic neuralgia, $P_{s} A$ psoriatic arthritis

\section{HZ Events and PHN}

Of the 36 first HZ events, 1 (2.8\%) patient had a serious event, $1(2.8 \%)$ patient had a severe event, and 1 (2.8\%) patient had a HZ event followed by PHN (Table 6). Recurrence of HZ was reported in one $(2.8 \%)$ patient, who experienced two non-serious HZ events. The second $\mathrm{HZ}$ event was moderate in severity and was not followed by PHN. Five patients reported their latest $\mathrm{HZ}$ event within 90 days of their last study visit, and two of these events were ongoing at the patients' last visit.

\section{HZ Management and Outcomes}

In response to the first $\mathrm{HZ}$ event $(N=36)$, tofacitinib treatment was temporarily discontinued in $66.7 \%$ of patients, with a mean (range) length of 14.3 (6-30) days, permanently discontinued in $2.8 \%$ of patients, and unchanged in $30.6 \%$ of patients (Fig. $4 \mathrm{a}$ ). Of the 36 first HZ events, 34 (94.4\%) resolved. Tofacitinib was temporarily discontinued in the single patient with a second $\mathrm{HZ}$ event, which resolved. Of all 36 patients experiencing a first HZ event, 88.9\% received anti-viral treatment for systemic use (Figure S2), most commonly aciclovir, which was used in $58.3 \%$ of patients; most anti-virals were received within 3 days of $\mathrm{HZ}$ onset.

For the 34 first HZ events, median and mean time to resolution was 20.5 days and 24.4 days, respectively, overall (Fig. 4b). Time to resolution was numerically lower for single dermatomal versus multi-dermatomal cases (median 19.0 vs. 24.0 days) and anti-viral use versus no use (median 19.5 vs. 51.5 days) (Fig. 4 b) but numerically higher for patients with corticosteroid use within 14 days prior to the event versus no treatment (median 25.5 vs. 19.5 days) and for those receiving an average dose of tofacitinib $10 \mathrm{mg}$ BID versus $5 \mathrm{mg}$ BID (median 28.0 vs. 19.0 days) (Fig. 4b). The longest duration of $\mathrm{HZ}$ was 58 days. In the patient with a second $\mathrm{HZ}$ event, this was a single dermatomal, which resolved after 11 days.

There were no deaths due to $\mathrm{HZ}$ in patients with PsA receiving tofacitinib, while seven deaths $(0.9 \%$ of $N=783)$ were reported due to other events, two of which occurred within 28 days of the last tofacitinib dose. Overall, 10 (27.8\%) patients with HZ were hospitalized, compared with 118 (15.8\%) patients without HZ. Of the ten patients with HZ who were hospitalized, one $(2.8 \%$ of patients with $\mathrm{HZ})$ was hospitalized specifically because of their $\mathrm{HZ}$ 

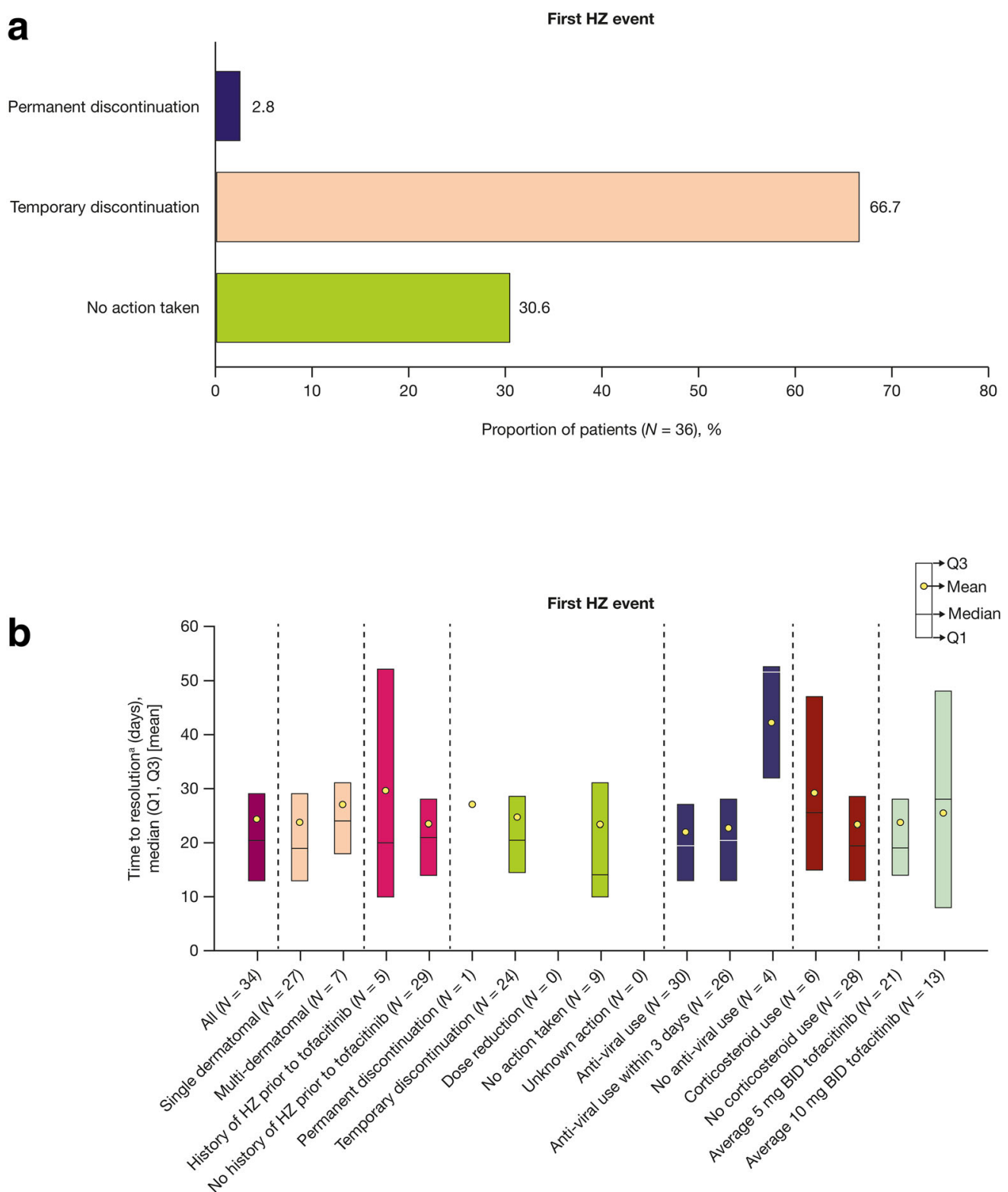

Fig. 4 Responses to $\mathrm{HZ}$ in patients with $\mathrm{PsA}$ receiving tofacitinib: a changes to tofacitinib treatment for first $\mathrm{HZ}$ event; $\mathbf{b}$ time to resolution ${ }^{\mathrm{a}}$ of first $\mathrm{HZ}$ event, stratified by dermatome involvement, history of $\mathrm{HZ}^{\mathrm{b}}$, changes to tofacitinib treatment, anti-viral use, corticosteroid use ${ }^{c}$, and average tofacitinib dose. ${ }^{a}$ Time to resolution in patients with both a date of onset and date of resolution

event while the remainder $(N=9 ; 25.0 \%$ of patients with HZ) were hospitalized because of other events. for the $\mathrm{HZ}$ event. ${ }^{\mathrm{b}}$ Medical history of $\mathrm{HZ}$ prior to the first dose of tofacitinib. ${ }^{\mathrm{c}}$ Corticosteroid use within 14 days prior to the $\mathrm{HZ}$ event. $B I D$ twice daily, $H Z$ herpes zoster, $N$ number of patients with non-missing data, $P_{s} A$ psoriatic arthritis, Q1 first quartile (25th percentile), Q3 third quartile (75th percentile)

\section{DISCUSSION}

This post hoc analysis provides the first detailed description of the management and outcomes 
of $\mathrm{HZ}$ events in tofacitinib RA and PsA clinical studies. HZ was experienced by $11.1 \%$ of patients with RA, with an IR $(95 \% \mathrm{CI})$ of 3.6 $(3.4,3.9)$ per $100 \mathrm{PY}$. These results were generally similar to IRs published for baricitinib and upadacitinib [21-23] and higher than rates reported for bDMARDs [24]. In patients with PsA, HZ was experienced by $4.6 \%$ of patients, with an IR $(95 \% \mathrm{CI})$ of $1.8(1.2,2.4)$ per $100 \mathrm{PY}$. The majority of first and second $\mathrm{HZ}$ events were non-serious, mild or moderate in severity, and resolved. The reported difference in $\mathrm{HZ}$ incidence between the RA and PsA cohorts may be due to variations in patient number, tofacitinib exposure, and follow-up times. In addition, baseline differences in the RA and PsA cohorts, including higher proportions of patients of Asian ethnicity and concomitant corticosteroid use, may have contributed to the observed differences as both have been previously identified as independent risk factors for HZ [12]. Older age has also previously been identified as an independent risk factor for $\mathrm{HZ}$ in patients with RA receiving tofacitinib [6]. In both RA and PsA cohorts, more patients with $\mathrm{HZ}$ events were aged $\geq 45-<65$ years versus those with no HZ events while the proportion aged $\geq 65$ years was similar.

Recurrence of $\mathrm{HZ}$ was observed in $8.0 \%$ of patients with RA and $2.8 \%$ of patients with PsA. By contrast, recurrent $\mathrm{HZ}$ is quite rare in the general population; the majority of individuals who have $\mathrm{HZ}$ never experience another event during their lifetime. Indeed, a populationbased analysis of $>17,000$ individuals who experienced one HZ event, followed over a total of $>1.8$ million person-years, found that $0.4 \%$ had a second HZ event; the lowest risk period for recurrence was within 12 months after the first event [25]. Based on the results of the current analysis, the risk of recurrent $\mathrm{HZ}$ under the conditions of JAK inhibition appears to be higher, suggesting that cell-mediated immunity associated with a first HZ event is not as robust or protective as observed in the general population. Alternatively, this could suggest that there are mechanisms for VZV reactivation, beyond diminished cell-mediated immunity, that may occur with JAK inhibition. In patients with RA, the IR of $\mathrm{HZ}$ in all patients who received tofacitinib was similar to the IR of a second $\mathrm{HZ}$ event in patients with a first $\mathrm{HZ}$ event, suggesting that risk is not increased following the occurrence of HZ. To ensure that the first HZ event had truly resolved and there was no overlap, the IR for second HZ events was calculated only for events occurring $\geq 30$ days after the first HZ event resolved. As such, two $\mathrm{HZ}$ events occurring in patients with $\mathrm{RA}<30$ days after the first $\mathrm{HZ}$ event resolved were not considered as recurrent; had these events been included, the IR would have been slightly lower as the follow-up time for all patients would have increased. The proportion of patients who had a second HZ event following temporary discontinuation of tofacitinib was similar to those who did not change their tofacitinib treatment, suggesting patients can continue treatment without increased risk.

A similar proportion of patients with RA experiencing a first or second $\mathrm{HZ}$ event temporarily discontinued tofacitinib or had no change to treatment. Conversely, in patients with PsA, the majority of patients temporarily discontinued tofacitinib treatment in response to their first HZ event. Few patients with RA or PsA permanently discontinued following $\mathrm{HZ}$ events. HZ outcomes, including HZ recurrence, were generally comparable for patients with RA who temporarily discontinued tofacitinib versus those with no treatment changes. Disease activity (as measured by DAS28-4[ESR]) for patients with RA was similar, regardless of any changes, or lack thereof, to their tofacitinib treatment including temporary discontinuation or continued without changes. By contrast, in a recent analysis of patients with RA who temporarily discontinued tofacitinib when receiving $\mathrm{HZ}$ vaccination, it was shown that disease activity worsened following withdrawal, but efficacy could be re-established when treatment was re-initiated [26]. Although the prescribing information for tofacitinib does not include recommended treatment adjustments in the event of $\mathrm{HZ}$ specifically, treatment interruption is recommended if patients develop a serious infection or opportunistic infection [27]. Temporary discontinuation is recommended in the prescribing information for baricitinib for patients with active HZ infection, while for 
upadacitinib the prescribing information states that temporary discontinuation should be considered in these patients $[28,29]$.

In this analysis, anti-viral treatments were used in $\sim 90 \%$ of patients with RA or PsA who developed $\mathrm{HZ}$ while receiving tofacitinib, consistent with guidelines that recommend antiviral use in immunocompromised patients with HZ [30, 31]. Patients with RA who received antiviral treatment following their first $\mathrm{HZ}$ event had similar outcomes to those who did not; however, the comparison was limited by the small number of patients who were not treated ( $\sim 10 \%)$. The majority of these patients received anti-viral treatment within 3 days of $\mathrm{HZ}$ onset, and similar outcomes were observed when considering only these patients who received early treatment.

While HZ events resolved in most patients, some events were reported as ongoing with no resolution date, and some patients with RA also had $\mathrm{HZ}$ events that lasted $>90$ days. It is possible that such events represented PHN. For primary care providers, PHN may not necessarily present as a distinct entity but rather an extension of the original HZ infection [32]. It is usually diagnosed in patients who have recovered from the HZ skin rash but who have continued to experience pain for at least 3 months [32]. The effectiveness of anti-viral treatment in treating or preventing PHN is uncertain [32, 33].

Interestingly, the median time to resolution of second $\mathrm{HZ}$ events was shorter than for first $\mathrm{HZ}$ events in the RA cohort analyzed. The reason for this is unclear, but it could be the result of boosted cell-mediated immunity following the first $\mathrm{HZ}$ event. This is consistent with a study in 401 healthy subjects, 60 of whom had recurrent $\mathrm{HZ}$ and reported milder clinical symptoms, likely because of stronger VZV cellmediated immunity, in recurrent versus primary HZ [34]. In the present analysis, there were some numerical differences in median time to HZ resolution when stratified by clinical characteristics and management. In both RA and PsA cohorts, patients with single dermatomal involvement (vs. multidermatomal involvement) and those who received anti-viral treatment (vs. those who did not) had a shorter median time to resolution of first $\mathrm{HZ}$ events.
Patients with RA and a history of HZ (vs. no history of HZ) or prior corticosteroid use (vs. no prior corticosteroid use) also had a relatively shorter time to resolution. Temporary discontinuation of tofacitinib (vs. no action taken) and prior corticosteroid use (vs. no prior corticosteroid use) were also associated with shorter time to resolution of second $\mathrm{HZ}$ events in patients with RA. However, patient numbers were small for some subgroups and so any numerical differences should be interpreted with caution. There were no deaths and few hospitalizations due to $\mathrm{HZ}$ in patients with RA or PsA.

While anti-viral therapy is recommended in immunocompromised patients with $\mathrm{HZ}$ [30], another effective management strategy is the prevention of disease through vaccination [35]. Although availability and approvals vary by country, two vaccines are available for use in patients aged $\geq 50$ years: a live zoster vaccine (LZV) [36] and an adjuvant recombinant subunit $(\mathrm{HZ} / \mathrm{su})$ vaccine [37]. LZV is contraindicated in patients who are immunocompromised [36]; there is currently no guidance regarding usage of $\mathrm{HZ} / \mathrm{su}$ in immunocompromised patients [37]. LZV efficacy has been shown to be limited [38] and reduce with increasing age [39]. While LZV was well tolerated in a study of patients with RA, the incidence of $\mathrm{HZ}$ was similar regardless of vaccination [16]. As such, there has been an increased focus on the $\mathrm{HZ} / \mathrm{su}$ vaccine, which appears to offer improved efficacy that does not decrease with increasing age [40].

Limitations of this analysis must be noted. This was a post hoc analysis of clinical studies that were not designed to assess clinical management of HZ. Sample sizes were limited, particularly for patients with PsA and for patients with a second $\mathrm{HZ}$ event. The analysis of time to $\mathrm{HZ}$ resolution did not account for whether antiviral treatment was received, except when stratified by anti-viral use. In addition, a proportion of $\mathrm{HZ}$ events $(\sim 15 \%$ for $\mathrm{RA}$ and $\sim 14 \%$ for PsA) occurred within 90 days of study discontinuation, and the limited followup period for these cases may have impacted the incidence of PHN or subsequent HZ events. 


\section{CONCLUSION}

In conclusion, although $\mathrm{HZ}$ risk is increased in patients with RA or PsA, and further increased with treatment with tofacitinib and other JAK inhibitors, this post hoc analysis demonstrated that $\mathrm{HZ}$ events in patients receiving tofacitinib were generally non-serious, mild or moderate in severity, and clinically manageable with events resolving in most patients. Further research is required to determine the mechanism by which tofacitinib increases $\mathrm{HZ}$ risk to optimize $\mathrm{HZ}$ management for tofacitinib and other JAK inhibitor-treated patients and to assess the efficacy and safety of the HZ/su vaccine in patients with RA or PsA receiving tofacitinib and other JAK inhibitors.

\section{ACKNOWLEDGEMENTS}

Funding. These studies were sponsored by Pfizer Inc. The journal's Rapid Service Fee for this article was also funded by Pfizer Inc.

Medical Writing and Editorial Assistance. Medical writing support, under the guidance of the authors, was provided by Sarah Piggott, MChem, and Gemma Turner, PhD, CMC Connect, McCann Health Medical Communications, and Kirsteen Munn, PhD, on behalf of CMC Connect, McCann Health Medical Communications, and was funded by Pfizer Inc, New York, NY, USA, in accordance with Good Publication Practice (GPP3) guidelines (Ann Intern Med 2015;163:461-464). The authors thank Rajneesh Singh (Covance) and Haiyun Fan (Pfizer Inc) for their statistical support.

Authorship. All named authors meet the International Committee of Medical Journal Editors (ICMJE) criteria for authorship for this article, take responsibility for the integrity of the work as a whole, and have given their approval for this version to be published.

Author Contributions. All authors were involved in drafting the article or revising it critically for important intellectual content, approved the final version to be submitted for publication, and agree to be accountable for all aspects of the work. KL Winthrop, JR Curtis, T Hirose, and $\mathrm{K}$ Kwok were involved in study conception and design. EB Lee, T Hirose, and GR Burmester were invoved in the acquisition of data. All authors were involved in the analysis/interpretation of data.

Disclosures. Kevin L Winthrop has received grant/research support from Bristol-Myers Squibb and is a consultant for AbbVie, BristolMyers Squibb, Eli Lilly, Galapagos, Gilead, GlaxoSmithKline, Pfizer Inc, Roche, and UCB. Jeffrey $\mathrm{R}$ Curtis has received grant/research support from Amgen, CorEvitas, Crescendo Bio, and Pfizer Inc and is a consultant for AbbVie, Amgen, Bristol-Myers Squibb, CorEvitas, Eli Lilly, Janssen, Myriad, Pfizer Inc, Roche/Genentech, and UCB. Kunihiro Yamaoka is a consultant for, and has received speaker fees and/or honoraria from, AbbVie, Actelion, Astellas, Chugai, Eisai, Eli Lilly, Gilead, GlaxoSmithKline, Janssen, Mitsubishi Tanabe, Nippon Shinyaku, Pfizer Inc, and Takeda. Eun Bong Lee is a consultant for Pfizer Inc, and has received research grants from GC Pharma and Handok Inc. Gerd R Burmester has received grant/research support from Pfizer Inc and is a consultant and a member of speakers' bureau for AbbVie, Eli Lilly, Gilead, and Pfizer Inc. Tomohiro Hirose, Jose L Rivas, and Kenneth Kwok are employees and shareholders of Pfizer Inc.

Compliance with Ethics Guidelines. The studies were conducted in accordance with the Declaration of Helsinki, the International Council for Harmonisation Guidelines for Good Clinical Practice, and local regulations. All patients provided informed consent, and Institutional Review Board approval was provided by all participating institutions.

Data Availability. Upon request, and subject to review, Pfizer will provide the data that support the findings of this study. Subject to certain criteria, conditions, and exceptions, Pfizer may also provide access to the related 
individual de-identified participant data. See https://www.pfizer.com/science/clinical-trials/ trial-data-and-results for more information.

Open Access. This article is licensed under a Creative Commons Attribution-NonCommercial 4.0 International License, which permits any non-commercial use, sharing, adaptation, distribution and reproduction in any medium or format, as long as you give appropriate credit to the original author(s) and the source, provide a link to the Creative Commons licence, and indicate if changes were made. The images or other third party material in this article are included in the article's Creative Commons licence, unless indicated otherwise in a credit line to the material. If material is not included in the article's Creative Commons licence and your intended use is not permitted by statutory regulation or exceeds the permitted use, you will need to obtain permission directly from the copyright holder. To view a copy of this licence, visit http:// creativecommons.org/licenses/by-nc/4.0/.

\section{REFERENCES}

1. Kawai K, Gebremeskel BG, Acosta CJ. Systematic review of incidence and complications of herpes zoster: towards a global perspective. BMJ Open. 2014;4:e004833.

2. Nagel MA, Gilden D. Neurological complications of varicella zoster virus reactivation. Curr Opin Neurol. 2014;27:356-60.

3. Yun H, Yang S, Chen L, et al. Risk of herpes zoster in auto-immune and inflammatory diseases: implications for vaccination. Arthritis Rheumatol. 2016;68: 2328-37.

4. Marra F, Lo E, Kalashnikov V, Richardson K. Risk of herpes zoster in individuals on biologics, diseasemodifying antirheumatic drugs, and/or corticosteroids for autoimmune diseases: a systematic review and meta-analysis. Open Forum Infect Dis. 2016;3:ofw205.

5. Harigai M. Growing evidence of the safety of JAK inhibitors in patients with rheumatoid arthritis. Rheumatology (Oxford). 2019;58:i34-42.
6. Winthrop KL, Yamanaka H, Valdez H, et al. Herpes zoster and tofacitinib therapy in patients with rheumatoid arthritis. Arthritis Rheumatol. 2014;66: 2675-84.

7. Burmester GR, Curtis JR, Yun H, et al. An integrated analysis of the safety of tofacitinib in psoriatic arthritis across phase III and long-term extension studies with comparison to real-world observational data. Drug Saf. 2020;43:379-92.

8. Winthrop KL, Lebwohl M, Cohen AD, et al. Herpes zoster in psoriasis patients treated with tofacitinib. J Am Acad Dermatol. 2017;77:302-9.

9. Mease P, Hall S, FitzGerald O, et al. Tofacitinib or adalimumab versus placebo for psoriatic arthritis. N Engl J Med. 2017;377:1537-50.

10. Gladman D, Rigby W, Azevedo VF, et al. Tofacitinib for psoriatic arthritis in patients with an inadequate response to TNF inhibitors. N Engl J Med. 2017;377: $1525-36$.

11. Cohen SB, Tanaka Y, Mariette X, et al. Long-term safety of tofacitinib up to 9.5 years: a comprehensive integrated analysis of the rheumatoid arthritis clinical development programme. RMD Open. 2020;6:e001395.

12. Winthrop KL, Curtis JR, Lindsey S, et al. Herpes zoster and tofacitinib: clinical outcomes and the risk of concomitant therapy. Arthritis Rheumatol. 2017;69:1960-8.

13. Winthrop KL, Harigai M, Genovese MC, et al. Infections in baricitinib clinical trials for patients with active rheumatoid arthritis. Ann Rheum Dis. 2020;79:1290-7.

14. Cohen SB, van Vollenhoven RF, Winthrop KL, et al. Safety profile of upadacitinib in rheumatoid arthritis: integrated analysis from the SELECT phase III clinical programme. Ann Rheum Dis. 2021;80: 304-11.

15. Harigai M, Honda S. Selectivity of Janus kinase inhibitors in rheumatoid arthritis and other immune-mediated inflammatory diseases: is expectation the root of all headache? Drugs. 2020;80:1183-201.

16. Calabrese LH, Abud-Mendoza C, Lindsey SM, et al. Live zoster vaccine in patients with rheumatoid arthritis treated with tofacitinib with or without methotrexate, or adalimumab with methotrexate: a post hoc analysis of data from a phase IIIb/IV randomized study. Arthritis Care Res (Hoboken). 2020;72:353-9.

17. Hodge JA, Kawabata TT, Krishnaswami S, et al. The mechanism of action of tofacitinib - an oral Janus 
kinase inhibitor for the treatment of rheumatoid arthritis. Clin Exp Rheumatol. 2016;34:318-28.

18. Kato M. New insights into IFN- $\gamma$ in rheumatoid arthritis: role in the era of JAK inhibitors. Immunol Med. 2020;43:72-8.

19. Bing N, Zhou $\mathrm{H}$, Chen $\mathrm{X}$, et al. Contribution of a European-prevalent variant near CD83 and an East Asian-prevalent variant near IL17RB to herpes zoster risk in tofacitinib treatment: results of genomewide association study meta-analyses. Arthritis Rheumatol. 2021;73:1155-66.

20. Bechman K, Subesinghe S, Norton S, et al. A systematic review and meta-analysis of infection risk with small molecule JAK inhibitors in rheumatoid arthritis. Rheumatology (Oxford). 2019;58: 1755-66.

21. Cohen S, van Vollenhoven R, Winthrop $\mathrm{K}$, et al. Safety profile of upadacitinib in rheumatoid arthritis: integrated analysis from the SELECT Phase 3 clinical program [abstract]. Arthritis Rheumatol. 2019;71(Suppl 10)

22. Winthrop KL, Takeuchi T, Burmester G, et al. Safety profile of baricitinib for the treatment of rheumatoid arthritis up to 8.4 years: an updated integrated safety analysis [abstract]. Arthritis Rheumatol. 2020;72 (Suppl 10).

23. Cohen SB, Van Vollenhoven R, Curtis JR, et al. THU0197 Safety profile of upadacitinib up to 3 years of exposure in patients with rheumatoid arthritis [abstract]. Ann Rheum Dis. 2020;79(Suppl 1):319-20.

24. Curtis JR, Xie F, Yun H, Bernatsky S, Winthrop KL. Real-world comparative risks of herpes virus infections in tofacitinib and biologic-treated patients with rheumatoid arthritis. Ann Rheum Dis. 2016;75:1843-7.

25. Qian J, Macartney K, Heywood AE, Sheridan S, Liu B. Risk of recurrent herpes zoster in a populationbased cohort study of older adults. J Am Acad Dermatol. 2021;85:611-8.

26. Kaine J, Tesser J, Takiya L, et al. Re-establishment of efficacy of tofacitinib, an oral JAK inhibitor, after temporary discontinuation in patients with rheumatoid arthritis. Clin Rheumatol. 2020;39: 2127-37.

27. US Food and Drug Administration. Xeljanz ${ }^{\circledR}$ (tofacitinib): highlights of prescribing information. 2019. https://labeling.pfizer.com/ShowLabeling. aspx?id=959. Accessed 2 Nov 2021.

28. US Food and Drug Administration. OLUMIANT (baricitinib): highlights of prescribing information.
2018. https://www.accessdata.fda.gov/drugsatfda docs/label/2018/207924s000lbl.pdf. Accessed 2 Nov 2021.

29. US Food and Drug Administration. RINVOQ ${ }^{\mathrm{TM}}$ (upadacitinib): highlights of prescribing information. 2019. https://www.accessdata.fda.gov/ drugsatfda_docs/label/2019/211675s000lbl.pdf. Accessed 2 Nov 2021.

30. Werner RN, Nikkels AF, Marinovic B, et al. European consensus-based (S2k) Guideline on the Management of Herpes Zoster - guided by the European Dermatology Forum (EDF) in cooperation with the European Academy of Dermatology and Venereology (EADV), Part 2: Treatment. J Eur Acad Dermatol Venereol. 2017;31:20-9.

31. Cates M, Donati M, Gillet S, Ustianowski A, Galloway J. Managing varicella zoster virus contact and infection in patients on anti-rheumatic therapy. Rheumatology (Oxford). 2018;57:596-605.

32. Massengill JS, Kittredge JL. Practical considerations in the pharmacological treatment of postherpetic neuralgia for the primary care provider. J Pain Res. 2014;7:125-32.

33. Saguil A, Kane S, Mercado M, Lauters R. Herpes zoster and postherpetic neuralgia: prevention and management. Am Fam Phys. 2017;96:656-63.

34. Nakamura Y, Miyagawa F, Okazaki A, et al. Clinical and immunologic features of recurrent herpes zoster (HZ). J Am Acad Dermatol. 2016;75:950-6.e1.

35. Harpaz R, Ortega-Sanchez IR, Seward JF. Advisory Committee on Immunization Practices (ACIP) Centers for Disease Control and Prevention (CDC). Prevention of herpes zoster: recommendations of the Advisory Committee on Immunization Practices (ACIP). MMWR Recomm Rep. 2008;57:1-30.

36. US Food and Drug Administration. ZOSTAVAX ${ }^{\circledR}$ (zoster vaccine live): highlights of prescribing information. 2019. https://www.fda.gov/media/ 119879/download. Accessed 2 Nov 2021.

37. US Food and Drug Administration. SHINGRIX (Zoster Vaccine Recombinant, Adjuvanted) suspension for intramuscular injection, highlights of prescribing information. 2017. https://www.fda. gov/downloads/BiologicsBloodVaccines/Vaccines/ ApprovedProducts/UCM581605.pdf. Accessed 2 Nov 2021.

38. Tseng HF, Harpaz R, Luo Y, et al. Declining effectiveness of herpes zoster vaccine in adults aged $>/=$ 60 years. J Infect Dis. 2016;213:1872-5. 
39. Oxman MN, Levin MJ, Johnson GR, et al. A vaccine to prevent herpes zoster and postherpetic neuralgia in older adults. N Engl J Med. 2005;352:2271-84.

40. Lal H, Cunningham AL, Godeaux O, et al. Efficacy of an adjuvanted herpes zoster subunit vaccine in older adults. N Engl J Med. 2015;372:2087-96.

41. Charles-Schoeman C, Fleischmann R, Davignon J, et al. Potential mechanisms leading to the abnormal lipid profile in patients with rheumatoid arthritis versus healthy volunteers and reversal by tofacitinib. Arthritis Rheumatol. 2015;67:616-25.

42. Kremer JM, Kivitz AJ, Simon-Campos JA, et al. Evaluation of the effect of tofacitinib on measured glomerular filtration rate in patients with active rheumatoid arthritis: results from a randomised controlled trial. Arthritis Res Ther. 2015;17:95.

43. Kremer JM, Bloom BJ, Breedveld FC, et al. The safety and efficacy of a JAK inhibitor in patients with active rheumatoid arthritis: results of a doubleblind, placebo-controlled phase IIa trial of three dosage levels of CP-690,550 versus placebo. Arthritis Rheum. 2009;60:1895-905.

44. Kremer JM, Cohen S, Wilkinson BE, et al. A phase IIb dose-ranging study of the oral JAK inhibitor tofacitinib (CP-690,550) versus placebo in combination with background methotrexate in patients with active rheumatoid arthritis and an inadequate response to methotrexate alone. Arthritis Rheum. 2012;64:970-81.

45. Fleischmann R, Cutolo M, Genovese MC, et al. Phase IIb dose-ranging study of the oral JAK inhibitor tofacitinib (CP-690,550) or adalimumab monotherapy versus placebo in patients with active rheumatoid arthritis with an inadequate response to disease-modifying antirheumatic drugs. Arthritis Rheum. 2012;64:617-29.

46. Tanaka Y, Suzuki M, Nakamura H, Toyoizumi S, Zwillich SH. Tofacitinib Study Investigators. Phase II study of tofacitinib (CP-690,550) combined with methotrexate in patients with rheumatoid arthritis and an inadequate response to methotrexate. Arthritis Care Res (Hoboken). 2011;63:1150-8.

47. Tanaka Y, Takeuchi T, Yamanaka H, Nakamura $H$, Toyoizumi S, Zwillich S. Efficacy and safety of tofacitinib as monotherapy in Japanese patients with active rheumatoid arthritis: a 12-week, randomized, phase 2 study. Mod Rheumatol. 2015;25: 514-21.

48. Conaghan PG, Østergaard M, Bowes MA, et al. Comparing the effects of tofacitinib, methotrexate and the combination, on bone marrow oedema, synovitis and bone erosion in methotrexate-naive, early active rheumatoid arthritis: results of an exploratory randomised MRI study incorporating semiquantitative and quantitative techniques. Ann Rheum Dis. 2016;75:1024-33.

49. Boyle DL, Soma K, Hodge J, et al. The JAK inhibitor tofacitinib suppresses synovial JAK1-STAT signalling in rheumatoid arthritis. Ann Rheum Dis. 2015;74:1311-6.

50. McInnes IB, Kim HY, Lee SH, et al. Open-label tofacitinib and double-blind atorvastatin in rheumatoid arthritis patients: a randomised study. Ann Rheum Dis. 2014;73:124-31.

51. Winthrop KL, Silverfield J, Racewicz A, et al. The effect of tofacitinib on pneumococcal and influenza vaccine responses in rheumatoid arthritis. Ann Rheum Dis. 2016;75:687-95.

52. Winthrop KL, Wouters AG, Choy EH, et al. The safety and immunogenicity of live zoster vaccination in patients with rheumatoid arthritis before starting tofacitinib: a randomized phase II trial. Arthritis Rheumatol. 2017;69:1969-77.

53. Burmester GR, Blanco R, Charles-Schoeman C, et al. Tofacitinib (CP-690,550) in combination with methotrexate in patients with active rheumatoid arthritis with an inadequate response to tumour necrosis factor inhibitors: a randomised phase 3 trial. Lancet. 2013;381:451-60.

54. van der Heijde D, Tanaka Y, Fleischmann R, et al. Tofacitinib (CP-690,550) in patients with rheumatoid arthritis receiving methotrexate: twelve-month data from a twenty-four-month phase III randomized radiographic study. Arthritis Rheum. 2013;65: 559-70.

55. Fleischmann R, Kremer J, Cush J, et al. Placebocontrolled trial of tofacitinib monotherapy in rheumatoid arthritis. N Engl J Med. 2012;367: 495-507.

56. Kremer J, Li Z-G, Hall S, et al. Tofacitinib in combination with nonbiologic disease-modifying antirheumatic drugs in patients with active rheumatoid arthritis: a randomized trial. Ann Intern Med. 2013;159:253-61.

57. van Vollenhoven RF, Fleischmann R, Cohen S, et al. Tofacitinib or adalimumab versus placebo in rheumatoid arthritis. N Engl J Med. 2012;367: 508-19.

58. Lee EB, Fleischmann R, Hall S, et al. Tofacitinib versus methotrexate in rheumatoid arthritis. N Engl J Med. 2014;370:2377-86.

59. Fleischmann R, Mysler E, Hall S, et al. Efficacy and safety of tofacitinib monotherapy, tofacitinib with methotrexate, and adalimumab with methotrexate 
in patients with rheumatoid arthritis (ORAL Strategy): a phase $3 \mathrm{~b} / 4$, double-blind, head-to-head, randomised controlled trial. Lancet. 2017;390: 457-68.

60. Wollenhaupt J, Lee EB, Curtis JR, et al. Safety and efficacy of tofacitinib for up to 9.5 years in the treatment of rheumatoid arthritis: final results of a global, open-label, long-term extension study. Arthritis Res Ther. 2019;21:89.
61. Yamanaka H, Tanaka Y, Takeuchi T, et al. Tofacitinib, an oral Janus kinase inhibitor, as monotherapy or with background methotrexate, in Japanese patients with rheumatoid arthritis: an open-label, long-term extension study. Arthritis Res Ther. 2016;18:34.

62. Nash P, Coates LC, Fleishaker D, et al. Safety and efficacy of tofacitinib up to 48 months in patients with active psoriatic arthritis: final analysis of the OPAL Balance long-term extension study. Lancet Rheumatol. 2021;3:E270-83. 